Vol. XXVI No 32020

\title{
ASPECTS REGARDING THE PRACTICAL REALIZATION OF AN ELECTRIC GENERATOR WITH AN ADAPTED MAGNETO AS AN ENERGY SOURCE
}

\author{
Marian JERLĂIANU*, Silviu Mihai PETRIŞOR*, Iulian BOULEANU** \\ *“Nicolae Bălcescu” Land Forces Academy Sibiu, Romania \\ **6"Lucian Blaga" University Sibiu, Romania \\ robmilcap@gmail.com
}

\begin{abstract}
In this paper, the authors want to highlight aspects related to the development, testing and use of an innovative technological product of the electric generator type with magneto, adapted for the production of heat and electricity. Its organology is based on a metal chassis to which is attached the heat engine and the generator with tensioner. The transmission of the rotational movement from the engine to the generator is done with the help of a V-belt. From a constructive point of view, the innovative aspect of the prototype is the adaptation of a moped-type electricity source, called here magneto, on a mobile generator structure that facilitates its independent and separate operation from the motors on which they are assembled. The heat engine has an installation attached to the section to exhaust the fumes resulting from the combustion of fuel. It accumulates heat that it releases into the outside environment. The tensioner allows the connection between the motor and the generator to be broken, allowing the motor to operate separately without generating electricity. The prototype has several constructive and functional advantages, such as: low mass, simple structure, energy efficiency and low operating noise.
\end{abstract}

\section{Keywords: prototype, electric generator, magneto, heat source}

\section{Introduction}

The energy represents "the capacity of a physical system to produce mechanical work when passing from one state into another given state" [1].

The electrical energy has a major importance and use in the $21^{\text {st }}$ century. This is due to the fact that humankind has developed production technologies that use such energy. The production of electrical energy can be achieved by transforming various forms of energy from the natural environment such as: mechanical energy, thermal energy, chemical energy, etc.

Thus, the inertia of the air masses is used for wind electrical generators and the solar energy is used for photovoltaic cells. Moreover, the fuels resulting from oil processing, by combustion, develop energies capable of producing mechanical work in a closed and well-adjusted space, so that the energy resulted from the thermal process is valorised as efficiently as possible. The heat engines have a multitude of component parts subjected to exploitations through mechanical and thermal phenomena and processes.

\section{Conception and practical realization of the prototype}

Capitalizing on the efficiency of heat engines has led to the development of a technological product for the production of heat and electricity. Its organology is based on a metal chassis on which are located the heat engine and the generator with 
tensioner. The mode of transmission of the rotation is made by a trapezoidal belt that moves on two pulleys of equal diameter. The motor pulley is the conductive one and the generator pulley is the driven one. The two ends of the tensioner are fixed, one to the top of the generator and the other to the chassis by rotating joints. The belt is tightened by unscrewing the nut on the screw and distancing the electric motor generator. The generator is built on a central shaft on which two bearings are fixed. At one end of it is a pulley fixed with a wedge and a screw screwed into the shaft. The rotor with permanent magnets, fixed to the conical screw, is located at the other end of the shaft. Three coils are placed in the magnetic field produced by the rotor. The lines of the variable magnetic field intersect the coil turns producing an electromotive voltage on each winding, according to the law of electromagnetic induction. "The value of magnetic induction is proportional to the thickness of the lines of force. Thus, the lines of force can give an idea of how the value of magnetic induction varies in different places" [2].

Coils can produce electricity both individually and jointly. The voltage at the generator terminals is alternative. The value of the voltage depends on the number of rotations.

The engine is a complex structure, which can convert thermal energy from combustion into mechanical energy. The technical data of the engine are presented in Table 1.

Table 1Engine technical data

\begin{tabular}{|l|l|}
\hline L-1-h & $313-376-335 \mathrm{~mm}$ \\
\hline Mass & $16 \mathrm{Kg}$ \\
\hline Volume & $196 \mathrm{~cm}^{3}$ \\
\hline Bore-Piston stroke & $68-54 \mathrm{~mm}$ \\
\hline Maximum output power & $4.1 \mathrm{kw}(5.6 \mathrm{hp}) \mathrm{la} 3600 \mathrm{rot} / \mathrm{min}$ \\
\hline Maximum engine torque & $12.4 \mathrm{Nm}$ la $2500 \mathrm{rot} / \mathrm{min}$ \\
\hline Motor oil & $0.6 \mathrm{~L}(10 \mathrm{w} 40)$ \\
\hline Fuel tank capacity & $3.1 \mathrm{~L}$ (gasoline) \\
\hline Consumption & $1.5-1.7 \mathrm{~L}$ at $3600 \mathrm{rot} / \mathrm{min}$ during $1 \mathrm{~h}$ \\
\hline Cooling type & Forced with air \\
\hline Ignition type & Magneto-transistorized \\
\hline Crank shaft rotation & Counter clock wise \\
\hline Heat released by burning gasoline & $33.1 \mathrm{MJ} / \mathrm{L}$ \\
\hline
\end{tabular}

This is the OHV (overhead valve) type. The operating principle is based on the four strokes specific to thermal engines: intake, compression, combustion, expansion and exhaust. With a cylinder capacity of 196 $\mathrm{cm}^{3}$, it can develop a power of $6.5 \mathrm{HP}$. The achievement of all the operating strokes is due to auxiliary systems and installations such as: supply, lubrication, distribution, ignition and cooling. The fuel supply is done by falling from the tank to the carburetor, due to the gravitational force of attraction, the latter making a homogeneous mixture of air-fuel in the intake manifold, having a constant level chamber. The gradual opening of the throttle allows the engine speed to be controlled. The engine lubrication system contains 0.61 of 10W40 oil, which ensures contact lubrication of the moving parts. "The oil is specially made to ensure high temperature lubrication, the engine, from a constructive point of view, being cooled by air" [3]. The main part responsible for lubrication is the crankshaft which, by striking the oil and throwing it around, lubricates all the parts with steam. The distribution is of the "wheel gears" type. The crankshaft, by rotation, transmits the movement to the camshaft by means of two wheels gears, which form a common 
body with the crankshaft and the camshaft, respectively. The cams, by construction in the body of the shaft, rotate and transmit oscillating motion to the rods towards the rocker arms responsible for opening and closing the valves in the cylinder head. "In order to prevent the cam wear, in the case of many engines the cams are protected by means of an anti-seize coating" [4]. The precise realization of the strokes is due to the valves, the process taking place as follows: during the intake, the intake valve is completely open; in compression, combustion and expansion, both valves are closed; finally, during the exhaust, the exhaust valve is open. "The valves open inside the cylinder to benefit from the pressure of the gases while they are closed (better sealing)"[5]. The ignition is of the magneto-transistorized type with coil and magnetic sector on the flywheel. When the permanent magnet passes by the coil, a strong electric current is generated and this determines the production of the electric spark between the spark plug electrodes in the combustion chamber. The running engine is cooled by a fan attached to the flywheel. "This, by rotation, creates air currents from the outside environment toward the engine cylinder provided with the fins necessary to increase the contact surface" [3]. Thus, the cylinder placed at $25^{0}$ from the horizontal dissipates the accumulated heat towards the external environment.

The valorization of the caloric capacity resulting from the combustion process is achieved by means of an installation that is directly attached to the exhaust opening of the cylinder. The installation includes: the flange that provides the connection to the cylinder, hose with metallic structure resistant to high temperatures, metallic four coil pipe body and malleable hose. Thus, after starting the engine, the system accumulates and releases heat.

At present, various types of magnetos are known, such as:

a) magnetos with a circular arrangement of a number of three coils (Fig. 1.a.), of fifteen coils (Fig. 1.b.) with a rotor with permanent magnets;

b) magnetos with two or three coils arranged in parallel as a constructive variant (Fig. 1.c).

But the models presented above have constructive disadvantages such as:

-fixed and non-detachable arrangement with respect to the engine for the production of electricity for which it was designed and made;

- the lack of minimum opportunities to make external electrical connections in order to capitalize on electrical energy separate from the electrical installations of the engines on which they are assembled and designed to operate.

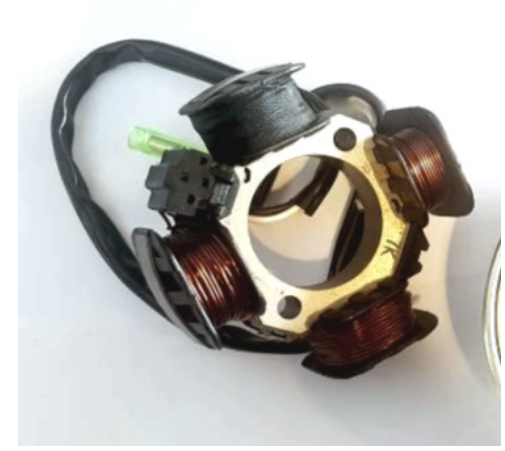

a. circular arrangement and three coils

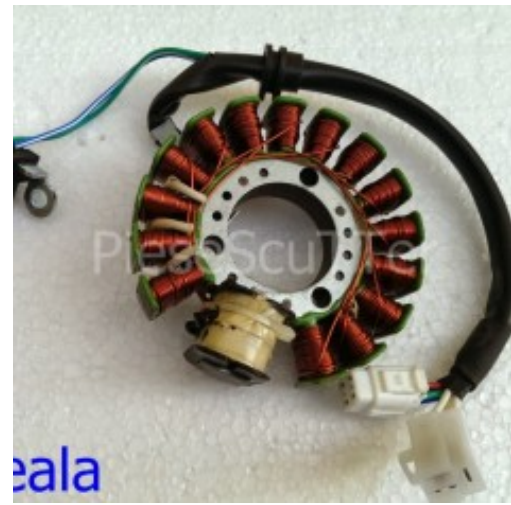

b. circular arrangement and fifteen coils

Figure 1: Type of magnetos

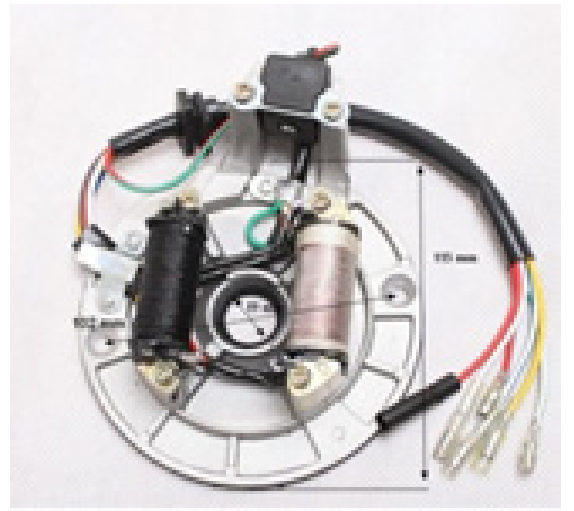

c. two coils arranged in parallel 
The innovative technological product, made in the Mechanical Engineering Laboratory, eliminates these disadvantages by adapting the stator assembly with rotor coils called magneto on a mobile and removable metallic structure in order to achieve the functioning through a variety of fastening methods (Fig. 2). At the same time, the electricity produced is practically open to the use of other electrical installations for electricity consumption, other than those intended for heat engines for which the magnetos were originally used.

The technical problem that the innovation solves consists in the maintenance in a favorable position, during operation, for lubrication and fueling. The lack of fueling would lead to the stopping of the engine, while the faulty lubrication would lead to stalling of the engine mechanism responsible for performing the mechanical

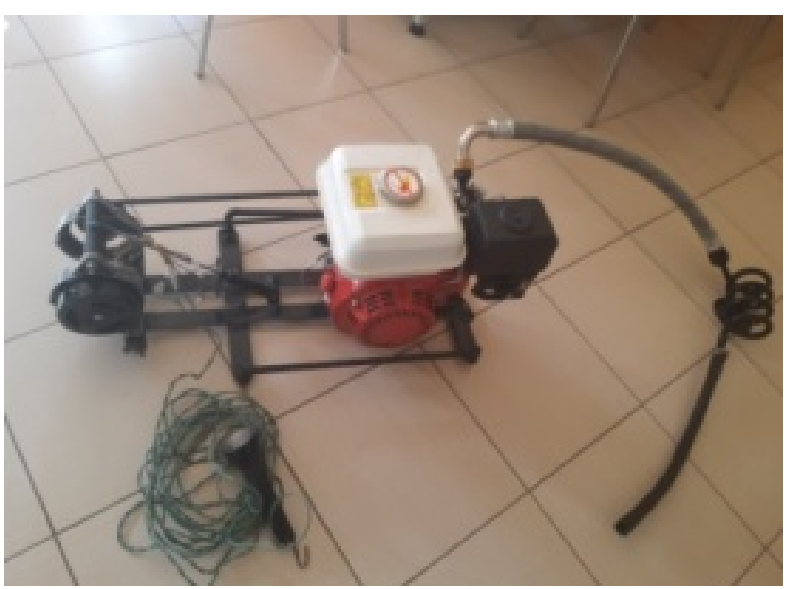

Figure 2: Magneto generator: metal chassis with heat engine and electric generator

The innovative technological product has a good and important use in the military environment. It can be used successfully under camping conditions, even at very low temperatures. It also has the possibility of producing electricity that can be used for lighting or for charging various batteries of electric accumulators. At the same time, the heating system based on the exhaust gases can be introduced in a confined space, thus ensuring a heat source. As far as the transport is regarded, it is required that it be kept in a position that prevents external leakage of liquids and that it be protected work. Among the claims of the present innovation we mention the following:

a. The prototype has the adaptation of the magneto as a separate energy source and specific to the uses of some electrical consumers. It is differentiated by the fact that the constructive variants of magnetos present on the market are used only on the engines on which they are mounted so that, by operating, the electricity that produced is valorized mainly by the engine and by a few small consumers;

b. The prototype has the possibility of decoupling the rotational movement from the engine to the generator (Fig. 3), due to the bolt tensioner differentiated by the fact that the electric generators of production line are manufactured in direct contact with the engine, which does not allow for their functioning separate from the engine.

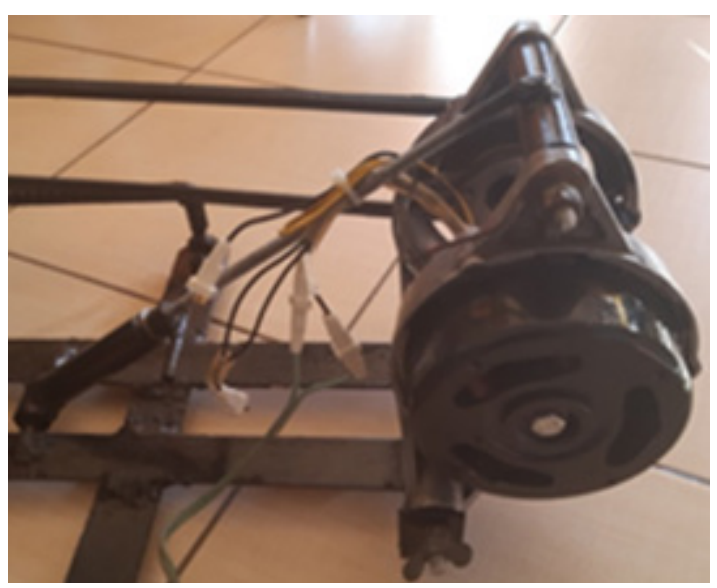

Figure 3:Electric generator

from very strong shocks. Table 2 presents a SWOT analysis of the realized prototype.

\section{Experimental results made obtained with the prototype}

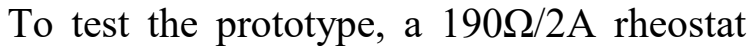
was connected to the terminals of the electric generator. By changing the rheostat values, load values $\left(R_{S}\right)$ between $20 \Omega$ and $120 \Omega$ were obtained. Before each measurement, the value of the $R_{s}$ load was measured with a UNI-T UT70 digital multimeter (Fig. 4.a). The generated voltage parameters were measured with a Rohde \& Schwarz digital oscilloscope type 
HMO1002 (Fig.4.b.). With its help was determined the shape of the generated signal, the frequency and amplitude peak to peak.

Table 2 SWOT Analysis

\begin{tabular}{|c|c|}
\hline Strengths & Weaknesses \\
\hline $\begin{array}{c}\text { - Low mass; } \\
\text { - Reduced fuel consumption; }\end{array}$ & $\begin{array}{c}\text { - The need to maintain a favorable position for } \\
\text { operation; }\end{array}$ \\
$\begin{array}{c}\text { - Equipped with heat supply installation; } \\
\text { - Possibility of operation under various } \\
\text { environmental conditions; } \\
\text { - Reliability for long-term use; } \\
\text { - Simple and efficient structure. }\end{array}$ & $\begin{array}{c}\text { - The risk of special liquid leaks in case of } \\
\text { neglect; }\end{array}$ \\
\hline Opportunities & $\begin{array}{c}\text { - Possibility of involuntary weakening of the } \\
\text { trapezoidal belt for transmitting rotations from the } \\
\text { engine to the generator; }\end{array}$ \\
\hline $\begin{array}{c}\text { - Long-term operation in case of use according } \\
\text { to the technical notes; }\end{array}$ & $\begin{array}{c}\text { - The heating system heats up excessively in } \\
\text { certain parts and injuries may occur. }\end{array}$ \\
$\begin{array}{c}\text { - Support of the armed forces in the station } \\
\text { district in order to restore combat or support } \\
\text { capabilities. }\end{array}$ & \\
\hline
\end{tabular}

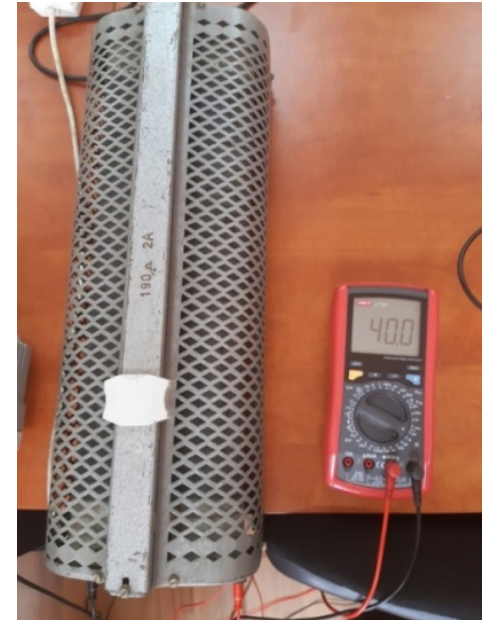

a. load measurement with the UNI-T UT70 multimeter

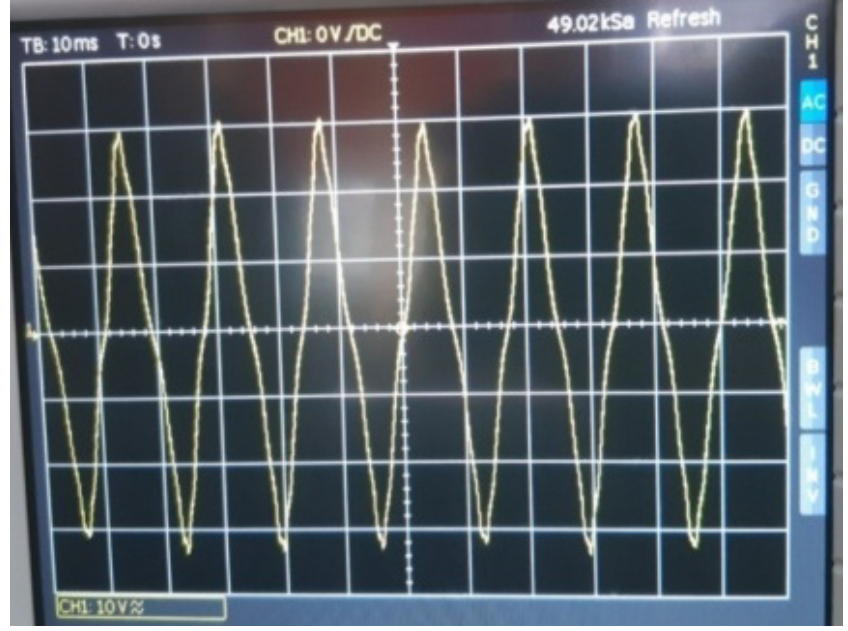

b. measuring parameters with the HMO1002 oscilloscope

Figure 4:Measuring the parameters of the electric generator

In Fig. 5 it is observed that, as the speed increases, the generator ensures higher electrical powers. It is also observed that the load values $R_{S}$ for which constant voltages are obtained at the output are dependent on the number of revolutions. At low speeds (800rpm) the output voltage remains constant for $R_{S}>80 \Omega$ values. At maximum speed (3600rpm), stable values of the generated voltage are obtained for $R_{S}>100 \Omega$.The number of rotations also has an effect on the frequency of the electromotive voltage. Thus, for $800 \mathrm{rpm}$, the generated voltage has a frequency of
$55 \mathrm{~Hz}$ and for $3600 \mathrm{rpm}$, the frequency is $200 \mathrm{~Hz}$.

\section{Conclusions}

This paper presents an innovative technological product of electric generator type with magneto, adapted for the production of heat and electricity. During the paper, aspects related to the development, testing and use of this type of electric generator were presented. The prototype is made on a metal chassis to which is attached a motor and the electricity generator. The transmission of the 
rotational movement from the motor to the generator is done by means of a V-belt. From a constructive point of view, the innovative aspect of the prototype consists in adapting a moped type electricity source, called here magneto, facilitates its independent and separate operation from the engines on which they are assembled. The heat engine has an installation attached to the section to exhaust the fumes resulting from burning fuel. It accumulates heat that it releases into the outside environment.

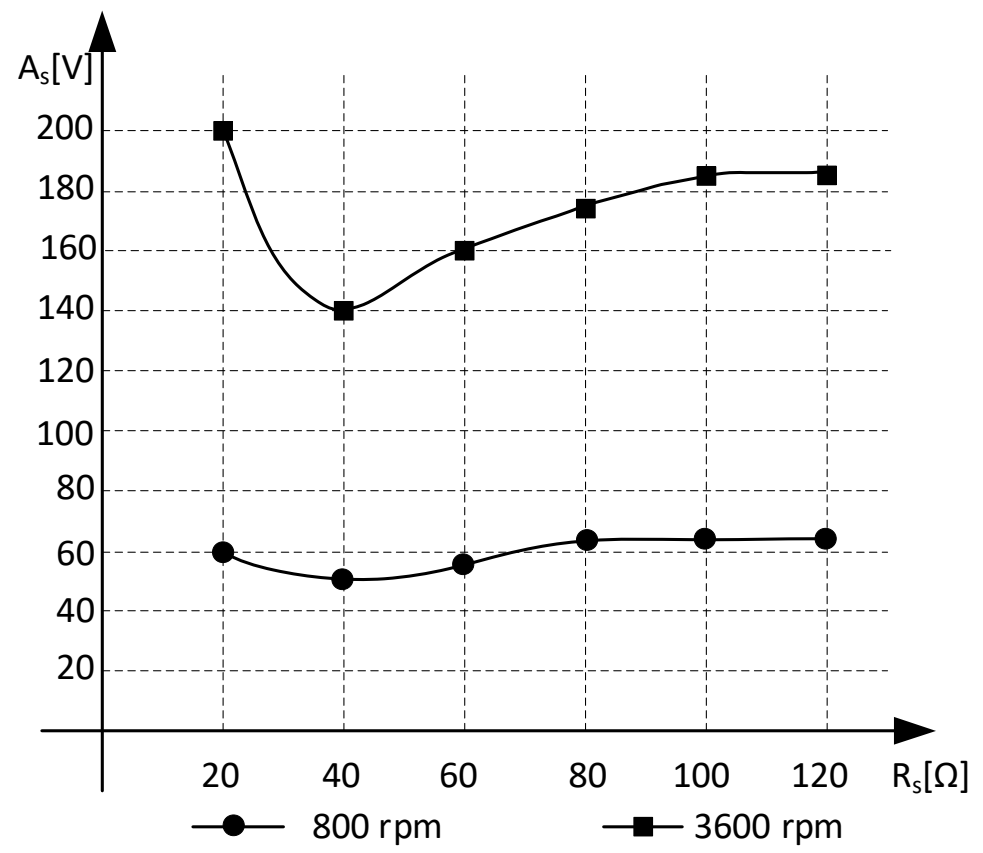

Figure 5: Dependence of the voltage generated by the load value and the rotation speed

The tensioner allows the connection between the motor and the generator to be broken, allowing the motor to operate separately without generating electricity. The prototype has several constructive and functional advantages, such as: low mass, simple structure, energy efficiency and low operating noise. The electric generator was tested in load and it was found that the amplitude and frequency of the electromotive voltage generated depends on the number of revolutions per minute and the value of the load.

The product can be used in camping conditions, even at very low temperatures. It can produce electricity that can be used for lighting or for charging various batteries. At the same time, the exhaust gasbased heating system can be introduced in a limited space, thus providing a heat source.

\section{References}

[1] https://dexonline.ro/definitie/energie, retrieved on 03.04.2020.

[2] Corodeanu I., Manolescu P., Buzatu C., Codru I, Electrotehnică Generală, p. 49, Editura Didactică şi Pedagogică, Bucureşti, 1967.

[3] Jerlăianu M., Electric Generator With Adapted Magneto And Heat Source Obtained From Exhaust Gases, The Scientific Bulletin Addenum, p. 292, „Nicolae Bălcescu” Land Forces Academy Publishing House Sibiu, 2020, ISSN 2501-3157.

[4] PitulescuGh., Intretinerea automobilului, p. 113, EdituraTehnică, Bucureşti, 1962.

[5] http://www.e-automobile.ro/categorie-motor/20-general/59-distributie-fixa.html, retrieved on 30.04.2020. 